\title{
Efficacy of Auto-PAP Titration in Obstructive Sleep Apnea: Single-center Experience
}

\author{
Amrutha S. Unnithan, G. Gokul Krishna', P. Hari Lakshmanan² \\ Department of Respiratory Therapy, Amrita Institute of Medical Sciences, Kochi, ${ }^{2}$ Department of Pulmonology, VPS Lakeshore Hospital and Research Centre, \\ Eranakulam, Kerala, ${ }^{1}$ Department of Respiratory Therapy, Manipal College of Health Professions, Manipal, Udupi, Karnataka, India
}

\section{Abstract}

Background: Obstructive sleep apnea (OSA) is a sleep-associated breathing disorder, which left untreated can cause severe morbidities or even mortality. The recommended treatment strategy for moderate-to-severe OSA is continuous positive airway pressure (CPAP). The optimal pressure required for OSA can be measured by either manual CPAP titration or auto-CPAP titration study. Objective: To assess the efficacy of auto-PAP titration for OSA patients. Methodology: This was a cross-sectional study conducted on Pulmonary Medicine Sleep Lab at Amrita Institute of Medical Sciences, Kochi. Fifty patients who have undergone full-night polysomnography and followed with auto-PAP titration are included in the study. The research was approved by the institutional ethics committee. Results: In the study cohort, 50\% showed optimal titration, $40 \%$ good titration, $10 \%$ adequate titration and none in unacceptable category. The results showed that auto-PAP usage has good result in moderate-to-severe OSA. Conclusion: Unattended auto-PAP titration seems to be highly effective modality which can be considered as an alternative to attended CPAP titration, thus reducing labor intensiveness and cost.

Keywords: Auto-positive airway pressure, continuous positive airway pressure, OSA

\section{INTRODUCTION}

Obstructive sleep apnea (OSA) is characterized by partial or full obstruction of the airway during sleep due to muscle relaxation causing soft-tissue collapse in the upper airway. Continuous positive airway pressure (CPAP) is the recommended treatment for OSA; it acts as a pneumatic splint in the airway and keeps it open. ${ }^{[1]}$ CPAP level required can be assessed either by manual CPAP titration or auto-titration. In manual titration, an attending clinician monitors the sleep pattern and increases or decreases CPAP level manually. In auto-PAP titration, the machine automatically adjusts for varying pressure requirement of patients. During the course of auto-PAP titration, one attending clinician should monitor the patient and minimize the chances of disconnection. Auto-PAP devices adjust treatment pressure by feedback control according to patterns of sleep and pressure requirement. Flow signals are measured during the treatment.

According to the American Academy of Sleep Medicine (AASM) guidelines, efficacy of CPAP titration is classified as follows: Optimal titration: Reduces Respiratory

\begin{tabular}{|l|l|}
\hline \multicolumn{2}{|c|}{ Access this article online } \\
\hline Quick Response Code: & Website: \\
\hline & www.ijrconline.org \\
\cline { 2 - 2 } & \\
\hline
\end{tabular}

Disturbance Index (RDI) $<5$ for at least a 15 min duration and should include supine rapid eye movement (REM: During this stage, the activity of the brain's neurons is quite similar to that during waking hours) sleep at the auto-titrated pressure that is not continually interrupted by spontaneous arousals or awakening. Good titration: Reduces RDI $<10$ or by $50 \%$ if the baseline RDI $<15$ and should include supine REM sleep that is not continually interrupted by spontaneous arousals or awakening. Adequate titration: Does not reduce RDI $<10$ but reduces the RDI by $75 \%$ from baseline, or one which the titration grading criteria for optimal or good are met with the exception that supine REM sleep did not occur at the auto-titrated pressure. Unacceptable titration: Titration is one that does not meet any one of the above grades. ${ }^{[2]}$

Address for correspondence: Mr. G. Gokul Krishna, Department of Respiratory Therapy, Manipal College of Health Professions, Manipal, Udupi, Karnataka, India. E-mail: gokulrescare@gmail.com

This is an open access journal, and articles are distributed under the terms of the Creative Commons Attribution-NonCommercial-ShareAlike 4.0 License, which allows others to remix, tweak, and build upon the work non-commercially, as long as appropriate credit is given and the new creations are licensed under the identical terms.

For reprints contact: reprints@medknow.com

How to cite this article: Unnithan AS, Krishna GG, Lakshmanan PH. Efficacy of auto-PAP titration in obstructive sleep apnea: Single-center experience. Indian J Respir Care 2020;9:68-70.

Received: $17-07-2019$

Accepted: 14-11-2019

Revised: 13-11-2019 Published: 08-01-2020 
Unnithan, et al:: AutoPAP titration in obstructive sleep apnea

\section{Methodology}

The present observational study was conducted over a period of 1 year (August 2016-August 2017) at the Pulmonary Medicine Department in Amrita Institute of Medical Science and Research Center, a multispecialty teaching and tertiary care hospital, Kochi, India. The study was approved by the Institutional ethical committee. Consecutive patients aged $>18$ years, who were diagnosed with moderate (apnea-hypopnea index (AHI) 15-29) to severe OSA (AHI $\geq 30$ ) with polysomnography (PSG) and who underwent auto-PAP titration were included in the study. Patients with overlapping conditions such as chronic lung disease or who were acutely ill (heart failure), mild OSA, already on noninvasive ventilation, and were not willing to participate from the study were excluded. Auto-PAP level ranged between $4 \mathrm{cmH}_{2} \mathrm{O}$ and $20 \mathrm{cmH}_{2} \mathrm{O}$. The pressure was automatically titrated by the auto-PAP machine. Philips Respironics Alice PDx and Resmed AirSense 10 auto-CPAP devices were used for the study.

\section{Outcome measures}

The primary outcome assessed was the efficacy of auto-PAP titration in moderate-to-severe OSA. Secondarily we also assessed association between body mass index (BMI), age distribution, neck circumference, and leak with titration efficacy groups.

\section{RESULTS}

Table 1 represents the demographic details of the patients. 50 patients were recruited in the study [Figure 1]. Of these, 45 were males. $73 \%$ of the study groups were obese (BMI $\geq 30$ ). Based on age, the patients were stratified into three groups, of which $58 \%$ of the study population with OSA had age between 40 and 59 years, respectively. PSG study showed 28\% of study population had moderate OSA and $72 \%$ had severe OSA. Table 2 represents the comparison of OSA severity

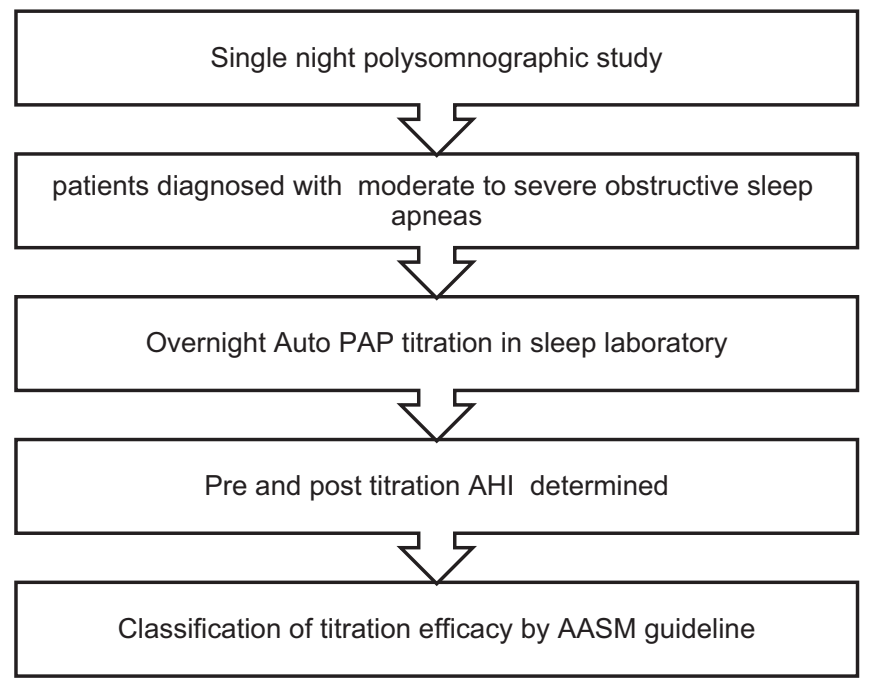

Figure 1: Schematic representation of study design with other measured indices. The mean respiratory distress index (RDI) was 25.5 vs. 48.8 in moderate and severe OSA group. Higher percentage of both moderate and severe OSA patients had more than 4 Epworth score for daily symptoms. Average snore index in patients with moderate and severe OSA was 214 and 354, respectively. The primary outcome variable (efficacy of CPAP) assessed with AASM guideline showed $25(50 \%)$ patients had optimal titration, 20 had good, and 5 had adequate titration. No one came under the category of unacceptable titration [Table 3]. Secondary assessments such as comparison of titration group versus the age distribution, BMI, neck circumference, and leak were measured and are reported in Tables 4 and 5.

\begin{tabular}{llc}
\hline \multicolumn{2}{l}{ Table 1: Demographic data } & \\
\hline Demographics & Category & $\boldsymbol{n}(\%)$ \\
\hline Gender & Females & $5(10)$ \\
& Males & $45(90)$ \\
BMI & Obese & $33(73)$ \\
& Nonobese & $17(37)$ \\
Age (years) & $18-39$ & $9(20)$ \\
& $40-59$ & $26(58)$ \\
& $>60$ & $15(22)$ \\
OSA severity & Moderate & $14(28)$ \\
(PSG finding) & Severe & $36(72)$ \\
\hline BMI: Body mass index, PSG: Polysomnography, OSA: Obstructive sleep \\
apnea
\end{tabular}

Table 2: Obstructive sleep apnea severity versus other measured data

\begin{tabular}{lcc}
\hline & \multicolumn{2}{c}{ OSA severity } \\
\cline { 2 - 3 } & Moderate & Severe \\
\hline Snore Index (mean) & 214 & 354.7 \\
Daily symptoms (Epworth scoring), $n(\%)$ & & \\
$<4$ & $3(21)$ & $3(8)$ \\
$\geq 4$ & $11(79)$ & $33(92)$ \\
RDI (mean) & 25.5 & 48.8 \\
\hline
\end{tabular}

OSA: Obstructive sleep apnea, RDI: Respiratory Distress Index

Table 3: Auto-positive airway pressure titration efficacy

\begin{tabular}{lc}
\hline Titration efficacy classifications & Number of patients, $\boldsymbol{n}(\mathbf{\%})$ \\
\hline Optimal & $25(50)$ \\
Good & $20(40)$ \\
Adequate & $5(10)$ \\
Unacceptable & 0 \\
\hline
\end{tabular}

\begin{tabular}{lccc}
\multicolumn{4}{l}{ Table 4: Age distribution versus titration efficacy } \\
\hline Age (years) & Optimal, $\boldsymbol{n}$ (\%) & Good, $\boldsymbol{n}$ (\%) & Adequate, $\boldsymbol{n}$ (\%) \\
\hline $18-39$ & $5(20)$ & $4(20)$ & 0 \\
$40-59$ & $13(52)$ & $9(45)$ & $4(80)$ \\
$>60$ & $7(28)$ & $7(35)$ & $1(20)$ \\
\hline
\end{tabular}


Unnithan, et al.: AutoPAP titration in obstructive sleep apnea

\begin{tabular}{|c|c|c|c|c|}
\hline \multicolumn{5}{|c|}{$\begin{array}{l}\text { Table 5: Mean body mass index, neck circumference and } \\
\text { leak in titration group }\end{array}$} \\
\hline \multirow{2}{*}{$\begin{array}{l}\text { Titration } \\
\text { group }\end{array}$} & \multicolumn{2}{|c|}{ BMI $\left(\mathrm{kg} / \mathrm{m}^{2}\right)$, mean BMI } & \multirow{2}{*}{$\begin{array}{c}\text { Neck } \\
\text { circumference } \\
\text { (inches) }\end{array}$} & \multirow{2}{*}{$\begin{array}{l}\text { Leak } \\
\text { (L/min) }\end{array}$} \\
\hline & $\begin{array}{c}\text { Obese } \\
>30\end{array}$ & $\begin{array}{l}\text { Nonobese } \\
\quad \leq 30\end{array}$ & & \\
\hline Optimal & 36.04 & 27.40 & 16.69 & 3.05 \\
\hline Good & 35.85 & 25.63 & 16.58 & 3.63 \\
\hline Adequate & 32.85 & 25.73 & 15.54 & 5.54 \\
\hline
\end{tabular}

BMI: Body mass index

\section{DISCUSSION}

OSA is a common disease condition with high prevalence in developed and developing countries. Epidemiological studies from USA showed almost 20 percent of adults have at least mild OSA and 7 percent of them have moderate-to-severe OSA with male predominance. ${ }^{[3]}$ Furthermore, data from Indian home sleep studies showed $7.5 \%$ of urban middle age men have OSA. Obesity and aging were the risk factors for OSA. Similar to these studies, the present study also observed the incidence of OSA was higher in males, aged between 40 and 59 years. One of the earliest studies on treating OSA with CPAP was done by Sullivan et al. in South Asian population. ${ }^{[4]}$ In their study, they observed significant difference in AHI with application of CPAP. Following this, the benefits of CPAP in OSA have been well studied and documented to be an effective strategy. ${ }^{[5-9]}$ Later, auto-PAP titration was introduced and has been studied extensively. Ortho et al. conducted a cohort study comparing the constant pressure with automatic pressure and found auto-PAP was as effective as constant CPAP in OSA. ${ }^{[10]}$ Ficker et al. conducted a study on auto-PAP versus constant CPAP and showed that auto-PAP was equally effective as manual CPAP. ${ }^{[11]}$ Another interesting finding was that the level of CPAP was higher in auto-PAP group compared to the constant CPAP. The primary objective of the present study was to assess the efficacy of auto-PAP. We found that $50 \%$ were optimally titrated, $40 \%$ showed good titration, $10 \%$ titrated adequately, hardly anyone in unacceptable efficacy category.

The secondary objective was to compare the association between BMI, age, and neck circumference and leak statistics with titration efficacy. We observed that the mean BMI, neck circumference, and leak were similar compared to the titration group. Ress et $a l^{[12]}$ and Mayer et al. ${ }^{[13]}$ showed that most of the baseline parameters have significant correlation with titration efficacy.

Major limitation of our study was lack of a comparative cohort, but study findings support the use of auto-PAP titration to reduce AHI. The scarcity of manpower resource is a major limitation of delivering quality care to patients and therefore in resource-limited settings, auto-CPAP titration can be recommended over manual CPAP titration.

\section{ConcLusion}

Unattended auto-PAP titration seems to be a highly effective modality that can be considered as an alternative to attended CPAP titration. Thus reduces labor intensiveness and cost.

\section{Financial support and sponsorship Nil. \\ Conflicts of interest}

There are no conflicts of interest.

\section{RefEREnCES}

1. Sforza E, Krieger J, Bacon W, Petiau C, Zamagni M, Boudewijns A. Determinants of effective continuous positive airway pressure in obstructive sleep apnea. Role of respiratory effort. Am J Respir Crit Care Med 1995;151:1852-6.

2. Kushida CA, Chediak A, Richard B, Brown LK, Gozal D, Iber C, et al. Clinical guidelines for the manual titration of positive airway pressure in patients with obstructive sleep apnea positive airway pressure titration. J Clin Sleep Med 2008;4:2.

3. Young T, Peppard PE, Gottlieb DJ. Epidemiology of obstructive sleep apnea: A population health perspective. Am J Respir Crit Care Med 2002;165:1217-39.

4. Sullivan CE, Issa FG, Berthon-Jones M, Eves L. Reversal of obstructive sleep apnoea by continuous positive airway pressure applied through the nares. Lancet 1981;1:862-5.

5. Loube DI, Gay PC, Strohl KP, Pack AI, White DP, Collop NA. Indications for positive airway pressure treatment of adult obstructive sleep apnea patients: A consensus statement. Chest 1999; $115: 863-6$

6. Indications and standards for use of nasal continuous positive airway pressure (CPAP) in sleep apnea syndromes. American Thoracic Society. Official statement adopted March 1944. Am J Respir Crit Care Med 1994;150:1738-45.

7. Jenkinson C, Davies RJ, Mullins R, Stradling JR. Comparison of therapeutic and subtherapeutic nasal continuous positive airway pressure for obstructive sleep apnoea: A randomised prospective parallel trial. Lancet 1999;353:2100-5.

8. Engleman HM, Kingshott RN, Wraith PK, Mackay TW, Deary IJ, Douglas NJ. Randomized placebo-controlled crossover trial of continuous positive airway pressure for mild sleep Apnea/Hypopnea syndrome. Am J Respir Crit Care Med 1999;159:461-7.

9. Oksenberg A, Silverberg DS, Arons E, Radwan H. The sleep supine position has a major effect on optimal nasal continuous positive airway pressure: Relationship with rapid eye movements and non-rapid eye movements sleep, body mass index, respiratory disturbance index, and age. Chest 1999;116:1000-6.

10. d'Ortho MP, Grillier-Lanoir V, Levy P, Goldenberg F, Corriger E, Harf A, et al. Constant vs. automatic continuous positive airway pressure therapy: Home evaluation. Chest 2000;118:1010-7.

11. Ficker JH, Wiest GH, Lehnert G, Wiest B, Hahn EG. Evaluation of an auto-CPAP device for treatment of obstructive sleep apnoea. Thorax 1998;53:643-8.

12. Rees K, Wraith PK, Berthon-Jones M, Douglas NJ. Detection of apnoeas, hypopnoeas and arousals by the AutoSet in the sleep apnoea/ hypopnoea syndrome. Eur Respir J 1998;12:764-9.

13. Mayer P, Meurice J, Philip-Joet F, Cornette A, Rakotonanahary D, Meslier N, et al. Simultaneous laboratory-based comparison of ResMed Autoset (TM) with polysomnography in the diagnosis of sleep apnoea/ hypopnoea syndrome. Eur Respir J 1998;12:770-5. 